\title{
POWOŁANIE KIEROWNICTWA BADAŃ NAD POCZĄTKAMI PAŃSTWA POLSKIEGO
}

\author{
ESTABLISHING THE DEPARTMENT FOR STUDIES \\ ON THE ORIGINS OF THE POLISH STATE
}

The Department for Studies on the Origins of the Polish State was established in 1949 in order to conduct extensive interdisciplinary research on the origins and functioning of the State of the First Piasts. The research project started a year earlier due to the necessity to celebrate a thousand years of the Polish State and the $1000^{\text {th }}$ anniversary of the Baptism of Poland. The process of "preparing the great anniversary", which was interpreted by the Catholic Church and the State in a different way and whose scientific aims were strongly influenced by politics, was undoubtedly the biggest initiative in the history of the Polish humanities research after World War II. These millennial studies have improved the state of our knowledge on the origins of the Polish statehood and the importance of Poland on the map of early medieval Europe. They also played an important social and political role in developing national consciousness of the Polish society after changing the borders in 1945 .

KEY WORDS: history of archaeology, studies on the origins of the Polish State

Obchodzona w 2016 r. rocznica 1050-lecia chrztu księcia Mieszka I przywołała inną, bardziej świeżą pamięć historyczną. Wiąże się ona z uroczystościami milenijnymi sprzed pół wieku, przebiegającymi w atmosferze sporu na linii państwo - Kościół, jaki zogniskował się wokół roku 1966 (Nosek 2002). Rzadko jednak w tamtych dyskusjach przypominani byli właściwi pomysłodawcy uczczenia tysiąclecia państwa polskiego i jego chrztu, tj. środowisko naukowe. To ono blisko 70 lat temu, w związku z przypadającymi w $1966 \mathrm{r}$. rocznicami, podjęło szeroko zakrojone badania nad początkami państwa polskiego, popularnie zwane milenijnymi. Zaplanowane dla rożnych dyscyplin działania miały na celu pozyskanie źródeł rzucających światło na genezę i funkcjonowanie państwa Pierwszych Piastów. Zniszczenia, jakie dotknęły wiele miast w okresie II wojny światowej, w tym te o dawnej, piastowskiej metryce, na czoło zadań badawczych wysunęły prace wykopaliskowe. Przy okazji, z przyczyn bardziej politycznych i społecznych, duży nacisk położono na „udowodnienie słowiańskości i prapolskości” ziem zachodnich i północnych, czyli tzw. Ziem Odzyskanych (przy- 
łączonych do Polski na mocy decyzji konferencji w Jałcie i Poczdamie), co miało uzasadnić nowy kształt terytorialny państwa.

Punktem wyjścia dla stworzenia programu badań milenijnych był artykuł 29-letniego archeologa, doktora Witolda Hensla pt. Potrzeba przygotowania wielkiej rocznicy, opublikowany w 1946 r. w poznańskim „Przeglądzie Wielkopolskim” (Hensel 1946), a następnie przedrukowany w formie oddzielnej broszury (Hensel 1946).

Problematykę tysiąclecia polskiego Witold Hensel zasygnalizował już dwa lata wcześniej, w odczycie pt. Spór polsko - niemiecki w sprawie powstania państwa polskiego (Wykłady 1944; Hensel 2001; Kośnik 2007, 220), który wygłosił w lubelskiej rozgłośni Polskiego Radia, w ramach cyklu 15-minutowych audycji popularyzujących historie Polski. Jednak sama koncepcja podjęcia planowych i zespołowych badań nad poczattkami państwa polskiego zrodziła się - jak wspominał po latach Witold Hensel $-\mathrm{w}$ trakcie prac archeologicznych, prowadzonych $\mathrm{w}$ rekonstruowanej po zniszczeniach wojennych katedrze poznańskiej, które ujawniły nieznane wcześniej relikty preromańskiej architektury, siegajace poczqtków polskiego chrześcijaństwa (Hensel 2004, 202). To doświadczenie pokazało mu, że $\mathrm{w}$ przeciwieństwie do historii, archeologia miała przed sobą wprost niewyczerpane możliwości zdobywania źródeł do badań nad słabo wówczas rozpoznanym wczesnym średniowieczem. $Z$ pracami archeologicznymi należało się jednak spieszyć, zanim postępująca odbudowa miast utrudni swobodne zakładanie wykopów. To samo dotyczyło wielu zabytków architektury, które już wkraczały lub niebawem miały wkroczyć w fazę rekonstrukcji, jak katedra poznańska czy kolegiata w Tumie pod Łęczyca. Na razie jednak ważna i wartościowa inicjatywa Witolda Hensla była tylko hasłem, któremu dopiero należało nadać konkretny kształt. Niezależnie od tego, $\mathrm{w}$ rozmaitych ośrodkach samorzutnie podejmowano prace wykopaliskowe $\mathrm{w}$ miejscach mających związek z genezą państwa polskiego.

Impulsy płynące $\mathrm{z}$ różnych stron doprowadziły w 1947 r. do podjęcia przez Naczelną Dyrekcję Muzeów i Ochrony Zabytków w Ministerstwie Kultury i Sztuki idei badań nad początkami państwa polskiego. 14 listopada 1947 r. na posiedzeniach komisji naukowej ${ }^{1}$ w Gnieźnie i Poznaniu, powo-

1 Komisja obradowała w następującym składzie: dr Michał Drewko (archeolog), doc. dr Aleksander Gieysztor łanej przez Ministra Kultury i Sztuki dla zbadania stanu prac archeologicznych $w$ Gnieźnie $i$ innych miejscowościach, ustalono, że kolejna konferencja z udziałem przedstawicieli różnych dyscyplin humanistycznych zajmie się opracowaniem szczegółowego programu badań nad wczesnym średniowieczem w związku z tysiącleciem państwa polskiego (AIAiEPAN, KBnPPP2 $, \mathrm{KB} / 8,3-2$ ).

Spotkanie, uznane później za programowe, któremu przewodniczył Stanisław Lorentz, dyrektor Naczelnej Dyrekcji i organizacyjny ojciec chrzestny badań milenijnych, odbyło się 1 marca 1948 r. w Warszawie (Protokół 1948, 406-412). Uczestniczyło w nim 33 uczonych: mgr Jerzy Antoniewicz (archeolog), prof. Włodzimierz Antoniewicz (archeolog), dr Maria Bernhard (archeolog), mgr Antoni Dębnicki (historyk), dr Michał Drewko (archeolog), doc. dr Aleksander Gieysztor (historyk), inż. Bohdan Guerquin (architekt), dr Witold Hensel (archeolog), dr Zbigniew Hornung (historyk sztuki), prof. Roman Jakimowicz (archeolog), prof. Rudolf Jamka (archeolog), mgr Alina Kietlińska (archeolog), mgr Witold Kieszkowski (historyk sztuki), prof. Józef Kostrzewski (archeolog), dr Gabriel Leńczyk (archeolog), dyr. dr Roman Lutman (historyk), prof. Kazimierz Majewski (archeolog), doc. dr Marian Małowist (historyk), prof. Tadeusz Manteuffel (historyk), prof. Kazimierz Michałowski (archeolog), dr Krystyna Musianowicz (archeolog), prof. Stefan Nosek (archeolog), dr Zofia Podkowińska (archeolog), dr Zdzisław Rajewski (archeolog), dyr. dr Tadeusz Reyman (archeolog), dyr. Ludwik Sawicki (archeolog), dyr. Bolesław Srocki (historyk), prof. Kazimierz Tymieniecki (historyk), prof. Michał Walicki (historyk sztuki), dr Zofia Wartołowska (archeolog), mgr Tadeusz Wieczor-

(historyk), inż. Bohdan Guerquin (architekt, historyk architektury), dr Witold Hensel (archeolog), inż. Aleksander Holas (architekt, konserwator zabytków), prof. Rudolf Jamka (archeolog), mgr Zdzisław Kępiński (historyk sztuki), mgr Witold Kieszkowski (historyk sztuki), prof. Józef Kostrzewski (archeolog), dr Gabriel Leńczyk (archeolog), dr Zdzisław Rajewski (archeolog), dyr. Ludwik Sawicki (archeolog), prof. Michał Walicki (historyk sztuki), inż. Jan Witkiewicz - Koszczyc (architekt). Obradom przewodniczył mgr Witold Kieszkowski.

2 Rozwinięcie zastosowanych skrótów: AIAiEPAN Archiwum Instytutu Archeologii i Etnologii Polskiej Akademii Nauk, KBnPPP - Kierownictwo Badań nad Początkami Państwa Polskiego. 
kowski (historyk), dr Adam Wolff (historyk), prof. Jan Zachwatowicz (architekt).

$\mathrm{Na}$ początku obrad docent doktor Aleksander Gieysztor wygłosił referat pt. Polskie Millenium. Z zagadnień wspótpracy historii i archeologii wczesnodziejowej (Gieysztor 1948, 391-406). Tekst ten powstał na prośbę Stanisława Lorentza i był głosem historyka mediewisty w dyskusji rozpoczętej przez archeologów w sprawie przygotowania wielkiej rocznicy. Nie wchodząc w szczegóły wystąpienia, Aleksander Gieysztor zaproponował w nim obszar badań i sposób ich realizacji w pełnej współpracy archeologów i historyków. Pracom archeologicznym w głównych ośrodkach państwa wczesnopiastowskiego miały towarzyszyć analizy źródeł pisanych dotyczących poszczególnych miejscowości. W procesie doboru obiektów do badań decydującą rolę przyznawał świadectwom historiograficznym. Przy czym, w opinii Aleksandra Gieysztora, prace należało skoncentrować przede wszystkim w Wielkopolsce i na tzw. Ziemiach Odzyskanych, a w mniejszym stopniu w Małopolsce, na Mazowszu czy Lubelszczyźnie.

W toku dyskusji podjętej po referacie Aleksandra Gieysztora zgromadzeni uczeni za niesporną uznali kierowniczą rolę problematyki historycznej w badaniach źródeł poznania polskich dziejów wczesnośredniowiecznych i wspólnie zaplanowali pierwszy etap prac archeologicznych. Wybrano obiekty w 11 miejscowościach ${ }^{3}$, które w sezonie wykopaliskowym w 1948 r. miały zostać objęte badaniami przez poszczególne ośrodki archeologiczne.

Oczywistym było, że nowa organizacja pracy, czyli planowe, interdyscyplinarne badania, wymagać będzie powołania instytucji zarządzającej. Pisał o tym Witold Hensel już w 1946 r. W jego opinii kierownictwo nad tym wielkim przedsięwzięciem naukowym miało należeć do Uniwersytetu Poznańskiego. W Poznaniu bowiem, jak podkreślał: nad tymi zagadnieniami pracuje caly szereg przedstawicieli rozmaitych dyscyplin. Poznań też ma historyczne do dzieła tego prawa. Tutaj bowiem ktadziono podwaliny pod gmach naszej państwowości. Tu byt najprawdopodobniej główny jej ośrodek dyspozycyjny, a na pewno siedziba pierwszego bi-

3 Gniezno, Poznań, Kruszwica, Ostrów Lednicki, Biskupin, Szczecin, Opole, Kraków - Zamek Królewski na Wawelu, Sobótka - kościół św. Jakuba, Gdańsk oraz Łęczyca. skupstwa polskiego (Hensel 1946, 15). A. Gieysztor proponował utworzenie dla planowanej inicjatywy badawczej osobnej placówki kierowniczej i organizacyjnej na wzór Centralnego Biura Inwentaryzacji Zabytków Sztuki (Gieysztor 1948, 403), tj. instytucji utworzonej w 1929 r. przy ówczesnym Ministerstwie Wyznań Religijnych i Oświecenia Publicznego, która koordynowała, jak również podejmowała prace nad gromadzeniem informacji o zabytkach sztuki w Polsce (Szablowski 1949, 79-83).

$\mathrm{Na}$ konferencji gnieźnieńskiej $\mathrm{w}$ listopadzie 1947 r. Stanisław Lorentz przedstawił pomysł powołania „Komitetu Badań Wczesnodziejowych przy Naczelnej Dyrekcji Muzeów i Ochrony Zabytków". Projekt założenia Komitetu przedyskutowano raz jeszcze, 1 marca 1948, w czasie konferencji warszawskiej (Gieysztor 1948, 405). Jednak zgromadzeni historycy i archeolodzy potraktowali problemy organizacyjne marginalnie - rozmawiano przede wszystkim o kierunkach badań, nieco uwagi poświęcono liście zgłaszanych kandydatur do Rady Naukowej mającej działać przy Komitecie (Protokół 1948, 406-412). Nie wzbudziła polemik istota sprawy, przedstawiona przez Aleksandra Gieysztora w referacie „Polskie Millennium” (Gieysztor 1948, 405-406). Autor wyjaśniał, że ulokowanie Komitetu przy sprawnym dziale administracji państwowej, czyli Naczelnej Dyrekcji, nie pozbawi go charakteru naukowego. Gwarantem miała być Rada Naukowa. Do tego: Komitet miałby zadania koordynacyjne dla imprez podejmowanych przez inne placówki, ale sam także zajmowałby się wykonawstwem. Mało przekonywająca była próba uspokojenia towarzystw naukowych i zakładów uniwersyteckich, które miały nie ponieść strat, ponieważ można ograniczyć zasadniczo zadania Komitetu tylko do wydobywania źródel naszej wiedzy oraz do składania sprawozdań z postęów prac. Słabość tego argumentu była tym bardziej widoczna, że Stanisław Lorentz jasno stwierdził w podsumowaniu obrad, iż zadania Komitetu leża $w$ dziedzinie planowania, koordynacji i kontroli (Protokół 1948, 411). Te szeroko pomyślane kompetencje pasowały raczej do organu administrującego nauką (nie instytutu naukowego).

Ustalenia podstaw prawnych, a przez to i finansowych przeciagały się w czasie. Niemniej zaplanowane na rok 1948 prace wykopaliskowe rozpoczęły się. Do czasu powołania instytucji kierującej, pieniądze na badania wyasygnowała lorentzowska Naczelna Dyrekcja Muzeów i Ochrony Zabytków, 
która wspierała projekt milenijny $\mathrm{w}$ tym czasie również administracyjnie.

Ostatecznie zarządzenie Ministra Kultury i Sztuki z 3 kwietnia 1949 (ogłoszone 19 czerwca 1949 r.) powoływało nie - jak planowano na konferencji - dziesięcioosobowy Komitet Wykonawczy (Protokół 1948, 411-412; AIAiEPAN, KBnPPP, KB/7, 2-6, 9), lecz Kierownictwo Badań nad Początkami Państwa Polskiego (AIAiEPAN, KBnPPP, KB/7, 7-8). Przewodniczył mu Aleksander Gieysztor, a współdziałali z nim Kazimierz Majewski i Zdzisław Rajewski. Prace realizowane pod ich kierunkiem finansowała Naczelna Dyrekcja Muzeów i Ochrony Zabytków. Przy Kierownictwie Badań od 10 grudnia 1949 r. działała Komisja Naukowa (AIAiEPAN, KBnPPP, KB/7, 21), bliska koncepcyjnie planowanej Radzie. W jej składzie znaleźli się kierownicy poszczególnych prac wykopaliskowych oraz ich zastępcy. Z dniem 1 stycznia 1950 r. oficjalnie rozpoczęło prace administracyjne Biuro KBnPPP, którym kierował Ryszard Kiersnowski. Kilkuosobowe Biuro zorganizowano w gmachu „Zachęty”, gdzie mieściła się wtedy siedziba Naczelnej Dyrekcji. Dalsze zarządzenie Ministra Kultury i Sztuki, z 20 czerwca 1950 r. (AIAiEPAN, KBnPPP, KB/7, 22-24), ustaliło strukture zespołu badawczego oraz zakres jego działalności. Powołano wówczas Biuro Inwentaryzacji Grodzisk, Pracownię Atlasu Wczesnodziejowego, Sekretariat Wydawniczy Kierownictwa Badań nad Początkami Państwa Polskiego w Warszawie, Nadzór Konserwatorski nad Pracami Wykopaliskowymi oraz 23 placówki terenowe Kierownictwa (AIAiEPAN, KBnPPP, sygn. KB/7). Ówczesne ekspedycje archeologiczne stały się więc Kierownictwami Prac Wykopaliskowych. W miarę potrzeb powoływano lub likwidowano kolejne placówki terenowe i pracownie specjalistyczne.

Dość szybko jednak wyszły na jaw zasadnicze niedomagania wspomnianej struktury, tj. nieustabilizowane zatrudnienie kadry naukowej oraz administratywny charakter aparatu centralnego Kierownictwa. Niemałą rolę odegrało w tym wszystkim znaczne rozszerzenie programu badawczego, a także brak stałego budżetu. Od końca 1950 r. czyniono więc starania o utworzenie nowej jednostki, tym razem instytutu naukowo-badawczego (Gieysztor 1953, 5). Działania te - co nie było również kwestią przypadku - zbiegły się w czasie z realizowaną przez władze komunistyczne przebudową nauki polskiej, która zmierzała do podporządkowania całości polskiego życia naukowego totalitarnej strukturze partii - państwa, centralizacji i narzucenia jej radzieckich wzorów instytucjonalnych i metodologicznych (Degen, Hübner 2006, 11-38; Stobiecki 2006, 127-155).

19 listopada 1953 r. na bazie Kierownictwa Badań nad Początkami Państwa powstał Instytut Historii Kultury Materialnej, z centralą w Warszawie, najpierw w ramach resortu Kultury i Sztuki, a następnie Polskiej Akademii Nauk (jego powołanie było urzeczywistnieniem wieloletnich dążeń środowiska prehistoryków do utworzenia państwowego instytutu archeologicznego) (Lech 2009, 193-214). Ponadto powstały cztery zakłady regionalne w: Krakowie, Poznaniu, Łodzi i Wrocławiu oraz pracownie regionalne w: Szczecinie, Wolinie, Kruszwicy, Kaliszu, Sandomierzu, Gdańsku i Igołomi. Z chwilą zlikwidowania Kierownictwa projekt milenijny był kontynuowany przez Instytut Historii Kultury Materialnej. Przy czym, ośrodek ten miał szerszy program badawczy, nie ograniczony tylko do wczesnego średniowieczna, choć „akcja przygotowania wielkiej rocznicy” nadal zajmowała wiele miejsca w jego działaniach (badania milenijne przejął przede wszystkim Dział I Archeologii Polski, kierowany przez Zdzisława Rajewskiego).

Działalność Kierownictwa Badań nad Początkami Państwa Polskiego (1949-1953) jak dotąd nie została $\mathrm{w}$ pełni opracowana. Już teraz trzeba przyznać, że jego rola była olbrzymia i może być obserwowana w wielu aspektach. Pierwszym i bez wątpienia najważniejszym jest aspekt merytoryczny. Kierownictwo skupiło nie tylko archeologów, ale i historyków (w mniejszym stopniu przedstawicieli innych dyscyplin humanistycznych), tworząc płaszczyznę wspólnych działań, przez co doprowadziło do integracji wysiłków obu grup badaczy nad problematyką polskiego wczesnego średniowiecza. To spowodowało, że wymienione nauki są obecnie wyraźnie inne, niż były przed badaniami milenijnymi. Dużym pożytkiem wynikającym z działań Kierownictwa był olbrzymi dorobek badań wykopaliskowych, których efekty zmieniły stan naszej wiedzy o początkach polskiej państwowości. Były jednak i pasywa akcji milenijnej, które do dnia dzisiejszego ciążą nad archeologią i historią. Szersza analiza tych zagadnień wykracza jednak poza ramy niniejszego artykułu. 


\section{BIBLIOGRAFIA}

Archiwum Instytutu Archeologii i Etnologii PAN (AIAiEPAN), Kierownictwo Badań nad Początkami Państwa Polskiego (KBnPPP), sygn. KB/7, KB/8.

Degan D., Hübner P. 2006. Polityka naukowa władz Polski Ludowej w zakresie humanistyki (1945-1990). (W:) U. Jankowska, J. Myśliński (red.), Humanistyka polska w latach 1945-1990. Warszawa, 11-38.

Gieysztor A. 1948. Polskie Millenium. Z zagadnień współpracy historii i archeologii wczesnodziejowej. Przeglad Historyczny 38, 391-412.

Gieysztor A. 1953. Kierownictwo Badań nad Poczatkami Państwa Polskiego w latach 1949-1952. Zapiski Archeologiczne 2, 1-56.

Hensel W. 1946. Potrzeba przygotowania wielkiej rocznicy. Poznań.

Hensel W. 1946. Potrzeba przygotowania wielkiej rocznicy. Przeglad Wielkopolski 2, 193-206.

Hensel W. 2001. Wyrwane kartki z pamiętnika - dwukrotny szczęśliwy los w listopadzie 1944 r. w Lublinie. Slavia Antiqua 42, 187-190.

Hensel W. 2004. Z historii powojennych badań w Poznaniu. Związek z genezą ruchu naukowego „Polskie Tysiąclecie" i jego perturbacje. Slavia Antiqua 45, 201-203.
Kośnik J. 2007. Lubelski etap działalności Witolda Hensla. Archeologia Polski 52/1-2, 219-225.

Lech J. 2009. O genezie i wczesnych dziejach Instytutu Historii Kultury Materialnej PAN wraz z uwagami do artykułu Imperium Atakuje pióra prof. Stefana K. Kozłowskiego. Przeglad Archeologiczny 57, 191-214.

Nosek B. 2002. „, Sacrum” czy „Profanum”? - spór o istote obchodów Milenium Polskiego (1949-1966). Warszawa.

[Brak inf. o autorze] 1948. Protokół na podstawie stenogramu z konferencji w Naczelnej Dyrekcji Muzeów i Ochrony Zabytków w dniu 1 III 48 r. w sprawie prac związanych z badaniem okresu powstania państwa polskiego. Przeglad Historyczny 38, 406-412.

Stobiecki R. 2006. Między kontynuacją a dyskontynuacją. (W:) U. Jankowska, J. Myśliński (red.), Humanistyka polska w latach 1945-1990. Warszawa, 127-155.

Szablowski J. 1949. Dzieje inwentaryzacji zabytków sztuki w Polsce: w dwudziestą rocznicę Centralnego Biura Inwentaryzacji Zabytków Sztuki. Ochrona Zabytków 2/2 (6), 73-83, 143.

[Brak inf. o autorze] 1944. Wykłady radiowe. Rzeczpospolita. Organ Polskiego Komitetu Wyzwolenia Narodowego $1,75,4$.

\section{ESTABLISHING THE DEPARTMENT FOR STUDIES ON THE ORIGINS OF THE POLISH STATE}

\section{SUMMARY}

The objective of this article is to introduce the issue of how the Supervision of Research on the Beginnings of the Polish Country was established. The institution was established pursuant to the 3 April 1949 Act of the Minister of Culture and Art regarding extensive interdisciplinary research on the genesis and functioning of the country of the first Piasts. The research was undertaken (already the year before) in relation to the need to commemorate the 1000-year anniversary of the existence of Poland and its baptism. The following 20 June 1950 Act of the Minister of Culture and Art defined the structure of the research team and the scope of its activities. This is when the Gord Inventory Office, Prehistoric Atlas, Publishing Office of the Supervision of Research on the Beginnings of the Polish Country in Warsaw, Conservation Supervision over Archeological Work, and 23 other local branches of the Supervision were established. Archeological expeditions carried out back then became the Supervision over Archeological Work. As the case may have been, local branches and specialized workshops were established or closed. However, fundamental weaknesses of the mentioned structure, i.e. lack of stability in the employment of research staff and the administrative nature of the central operation of the Supervision, did not take long in coming to light. Expansion of the research program and the lack of permanent budget also played an important role in the whole matter. Since the end of 1950 attempts were being made to form another unit, a scientific and research institute. On 19 November 1953, on the foundation of the Supervision of Research on the Beginnings of the Polish Country, the Material Culture History Institute, based in Warsaw, was established. 
Adres Autorki:

Dr Adrianna Szczerba

Instytut Archeologii

Uniwersytet Łódzki

ul. G. Narutowicza 65

90-131 Łódź

e-mail: adaszczerba@uni.lodz.pl 